\title{
The Tip Perception of the Hotel Employees: Wage or Reward?
}

\author{
Tuğba PALA ${ }^{1}$
}

https://orcid.org/0000-0001-8346-9901

\begin{abstract}
The "tip" phenomenon attracts the attention of various disciplines such as economics, sociology and psychology while it is a voluntary payment added on the service fee. A vast majority of the research on tipping examine the tipping behavior and motivation of the customers in the light of customer responses. There is a limited number of studies examining the "tip" phenomenon from an employee perspective. The aim of this study is to determine the tipping perceptions and beliefs of the employees who communicate face-to-face with customers and work in the hotel industry in Turkey. Our study reveals the meaning of tipping for hotel employees, the dynamics that determine the customers'tipping behavior and the strategies that employees use to get a tip, considering the experience of the employees who worked/are working in a five-star hotel.
\end{abstract}

Keywords: Tip, hotel employee, tipping behavior, reward, wage.

Jel Codes: J00, L83, M10

\section{Introduction}

Although tourism industry plays and important role in the economy (Isik et al., 2017), labor in the tourism sector is generally known as with low wages and high working hours. Those who work in the tourism sector mostly live with minimum wages and especially tips. The low wages of tourism sector cause employees need tip for a living. Therefore, tipping for tourism workers is of great importance in the tourism sector.

Tipping is usually a voluntary payment to the service employees made by the individual purchasing the service. While it is made on a volunteer basis and usually given in exchange for personal service, it is perceived as a sign of satisfaction and/or a special thanking. However, the increasing role of the tip in the labor economics shows that it has a meaning far beyond a special gift given in return to personal satisfaction. Tipping has an economically important place considering its position in the relationship between service recipient-employee-employer. Especially in the USA, it is estimated that approximately $\$ 47$ billion of tips are given to restaurant employees annually (Azar, 2011). Tips are mostly given to employees within the service sector such as waiters, taxi drivers, tour guides, doormen, food deliverymen, parking valets and bartenders (Star, 1988). In Turkey, tipping is a common behavior, especially in the hotel industry.

Studies on tipping have been the subject of different disciplines such as marketing (Tse, 2003), sociology and social psychology (Azar, 2004; Lynn, 1997), economics (Azar, 2003; Ferguson et. al., 2017) and management (Curtis et. al., 2009). When the literature is examined, it is seen that studies generally examined why customers tip (Azar, 2004; 2010; Lynn, 2015; 2016; Lynn \& McCall, 2016;), tipping behavior and factors affecting the amount of tip (tip size) (Parett, 2015; Lynn, Adams \& Douglas, 2008; Seiter, 2007; Bujisic, et. al., 2013; Curtis et. al. 2009; Jacob et. al., 2010; Seiter et. al., 2018; Gueguen \& Jacob, 2014). These studies investigate the situations in which customers tip and factors affecting their tipping behaviors. There are a limited number of studies that discuss the issue from the viewpoint of employees. In this study, it is aimed to investigate the perception of employees about tipping considering their experiences. Moreover, the study discusses how employees perceive the tip, in which cases they get a

\footnotetext{
${ }^{1}$ Araş. Gör. Dr., Mersin Üniversitesi, Turizm Fakültesi, Turizm İşletmeciliği Bölümü, tugbapala82@gmail.com
} 
tip and which strategies they use to get the tip. The results obtained from this study will contribute to the hospitality literature by revealing what the tip means to hotel employee. Although there are some studies examining the meaning of the tip, there is still a gap understanding what tip means for hotel employee in the hospitality literature. Moreover, as a practical implication for hotel managers, findings of the study can be an advisor to solve problems about tipping and tipping systems (individual or pooled tipping).

\section{Literature Review}

Tipping behavior has a complex structure consisting of different and various motivating factors (Lynn \& Graves, 1996). When the literature on tipping is examined, a number of studies are found related to what motivates the customers to tip. "Why people are tipping" is the most important question while investigating the situations in which customers willing to tip (Azar, 2010a). Studies conducted to examine the tipping motivation of customers show that customers do not tip strategically in order to receive better service in the future, it is found that their motivation to tip is only social and psychological (Azar, 2010a). These social motivations are to show gratitude, to follow the social norms and to make a contribution to the tip income of the employee (Azar, 2010b). Due to these three favorable reasons, customers provide positive psychological benefits. Negative consequences that occur when we don't tip, which are within other tipping reasons, may affect our motivation to tip less. Among these reasons; getting rid of the feeling of shame and guilt is a more important motivation than avoiding bad service in the future or being scolded by the employee. These results show that psychological and social motivations are more determinative in giving tips. Accordingly, Lynn \& McCall (2016) wondered why we tip more and they found that the bill size is the most important factor determining the amount of tip as a result of the meta-analysis they conducted to investigate why people tip and which factors affect their tipping decisions. The factors that determine the amount of tip after bill size are; server's attractiveness, server's friendliness and the customer's mood during the service encounter (Lynn \& McCall, 2016). As it is seen, the studies are about how the quality of service is evaluated from the perspective of the customer and which factors the customers attach importance to when giving tip or determining the amount of tip.

Studies that examine the tipping behavior and the factors that affect the amount of the tip generally focus on the appearance or the behaviors of the server. In studies discussing whether the appearance enhances the tip or not show that beauty increases the amount of the tip (Parret, 2015), well made-up women get more tips from male customers (Jacob et al, 2010), waitresses wearing red get more tips from male customers based on the determination that red color makes women more attractive to men in the previous studies (Gueguen \& Jacob, 2014). Considering the studies investigating whether the employee behaviors affect tipping or not, it has been asserted that compliment (Seiter, 2007), real smile (Bujisic, Wu, Matilla \& Bilgihan, 2013), giving the remaining food packaged by the waiter to the customer (Seiter \& Weger, 2018) increase the tipping. Nevertheless, even music playing in the restaurant can be effective in tipping. For example, prosocial lyrics of a song can give a positive effect on tipping by enabling customers to empathize (Jacob, Guegen \& Bolbry, 2010). In addition, it is claimed that the tip is given for reasons such as contributing to the low wages of the employees (Crespi, 1947), showing the status/power, being a gift given to the employee by the customer (Shamir, 1984).

As noted earlier, while most of the studies on tipping examined the phenomenon from the customer's perspective, there are a limited number of studies that take the opinions of employees into account. Tipping can be an effective way to establish a wage-cost balance and management can sometimes provide an indirect control through tip over employees who communicate face-to-face with the customer (Ogbonna \& Harris, 2002). However, employees prefer getting tip and customers like tipping while tipping has a positive effect of employees' affactive state and customers see the tip as an expression of satisfaction (Saunders, 2015; Mulinari, 2016). As for the employees' tipping system preference, employees see the pooled system as the most unfair, worst system in terms of distributional justice and they consider the tipping system that contains service charge as the fairest system (Namasivayam \& Upneja, 2008). Studies dealing with the topic of tipping from the perspective of the employees are about how employees consider the tip or which tipping system they prefer. Based on the experience of the employees, there is no study that deals with all aspects of how employees perceive the tip, why customers tip and which strategies employees prefer to get tips. Therefore, the purpose of this study is to try to understand what the tip concept means for the employees especially in the hotel industry. For this purpose, the research questions that will guide the 
study are: (1) How do employees perceive the tip? (2) What consequences does employee perception have in practice concerning tipping? (3) When do customers tip according to employees? (4) What are the strategies that employees develop concerning tipping?

\section{Method}

Providing a deeper examination of the tip phenomenon, which has a complex structure, is only possible with qualitative research. Exploratory researches are the researches that the researcher does not know much about the subject and wants to examine the subject in depth (Altunışık et al., 2012). In-depth semi-structured interviews are made with 31 hotel employees worked in front desk and/or restaurant departments in various tourism enterprises in Turkey. In this study, employees who have seen different tipping systems were asked to be included, since it is important that employees have different experiences about tipping; therefore, especially participants who have at least two years of experience in total in more than two enterprises were included. In addition, participants, who worked at a five-star, not all-inclusive (half pension or full pension) hotels in various tourism regions (Antalya, Bodrum, Marmaris) and who have seen different business styles, were selected. The snowball sampling method was used in sample selection. In addition to difficulty to reach people willing to interview, the fact that the limit of individuals who are members of the universe is not fully known is the reason for choosing this method (Patton, 2005). Although all the interviewees worked in different departments of the hotels, 5 participants worked also in restaurants in addition to their experiences. The interviews were made face to face between May 2019 and October 2019. The interviewees have working experiences between 2 and 10 years. Their ages range from 20 to 32. The length of these interviews is between 25 and 45 minutes. Interviews were recorded with the permission of the participants and these interviews were transcribed verbatim directly after the interview. These records consist of a total of 74 pages. Transcripts related to the interviews were reviewed by the author many times and subjected to content analysis. To ensure the validity and reliability of the analysis results, the qualitative research technique was used and the data were analyzed and coded independently by an accomplished scholar who follows the literature well. By comparing the codes coming from the expert with the codes made by the author, a consensus was reached between the codes.
Of the 31 participants in this study, 21 participants are male and 10 participants are female hotel employees. Although they have worked in different departments in the five-star hotels they have worked before, 10 participants work in the front office department of the hotel, 21 participants work in the restaurant department of the hotel. In addition, among participants, one of them is the front desk chief and two of them are F\&B chief (1 restaurant chief and 1 bar chief). In order to avoid any confusion, the quotations in which we include the direct sentences of the participants, only the name of the last position of the employee is given.

\section{Findings}

Findings obtained as a result of the interviews; themes were gathered under what the tip is in perspective of employees, employees' opinions about when customers tip and the strategies formed by the employees to get a tip. Under these main subjects, the feelings, thoughts and experiences of the employees with their own sentences will be included and their perspective on the tip will be detailed.

\subsection{Tip: Wage? or Reward?}

The tip, derived from the Persian word "bahş" and settled into the Turkish language, means to bestow, give gratuitously. According to TDK (Turkish Language Association), tip means"extra money apart from the fee paid for a service". In English, according to the Oxford dictionary, tip means "extra money; a small amount of extra money you give to someone serving you". In the $16^{\text {th }}$ century, in the UK, it is claimed that the tip was first introduced by throwing money into coffee cups written 'to ensure promptitude (tip)' to get faster service in 'cafes or bars' (Segrave, 2009). Origin of the word and cultural differences also show that the tip is not a simple phenomenon with a fixed reference. On the one hand, tipping is seen as a tool that expresses the satisfaction of the giver or a reward; on the other hand, it is considered as a fee in return of the service, a wage for the labor (Mulinari, 2016). In a similar vein, the findings of this study show that employees consider the tip as a wage and customers consider it as a reward. Also, this study emphasizes the misperception of considering the tip as a reward. Especially in our language and culture, understanding the "tip" word as the privilege of granting may be the reason why employees insistently remark the tip as part of the wage they deserve. This difference in perception can become quite evident considering the perception of tipping between USA and Turkey. In the light of the 
findings obtained from the participants, it can be said that in the USA, tipping is interpreted as an essential part of the wages of the employees, but in Turkey, it is accepted as a magnanimity of the customer. Therefore, almost all of the participants stated that when they received their first tip, they were embarrassed but then got used to it. For example, Participant 5 expresses this situation as follows:

When I first got a tip, I thought why this guy gives me money. I questioned whether I need this man's money. I felt it when I first got it. Now I think of what to do to get more money from him (Participant 5, male, waiter).

The following statements of Participant 9 also confirm the differences between societies of US and Turkey regarding the perception of tip:

In fact, I am more embarrassed when getting a tip from the Turks. We speak the same language, we are closer, more sincere with them (Participant 9, female, barmaid).

A group of employees stated that they felt embarrassed while getting a tip despite all their experience:

I'm very embarrassed when I wait in front of a person, because I feel like I'm waiting for the money (Participant 11, male, bellboy).

Of course, you will be embarrassed. Someone is passing something into your hand. Even if I work much longer, I can't look at the money in my palm. I can't look at it whether it's fake, 10 lira or 100 lira. I throw it into my pocket before looking at it, after that, I look at it (Participant, 12, male, bellboy).

We can say that the question of what a tip is has a direct connection with the motivation of the tipping; however, the customers and the employees getting tip don't have the same opinion with regard to tipping. Mulinari (2016) also suggested that while employees see the tip as part of their income, customers consider the tip as a reward for promoting good service after evaluating the service.

\subsubsection{Wage}

Many of the participants stated that they consider the tip as; a return of their work, a fee they deserved, money received for their efforts, the cost of extra service and extra earning. The statement of the participants, who see the tip as a fee, is as follows:

They give you the price for the extra service you do. They pay the fee you deserve. So, now the more you care about the guest, the more you please the guest, the guest returns the favor. But it has to be a conscious customer. There are also customers who don't care at all, I've also heard customers saying that they already get their salary, why do we pay more for this? (Participant 4, female, waitress)

You don't get this (tip) for free, you deserve it. Customers should make you feel like you have the right to get it just like your salary. For example, the tip is his/ her right to get like people getting their salary, he/she served, this has to be its exchange, customers should give this feeling (Participant 13, male, receptionist).

Due to the nature of service, it is difficult for businesses to control the service encounter and evaluate the service in the works that are communicated face to face with the customer (Shamir, 1984; Parasuramann, 1988). Therefore, the tip is thought to be used by the customer to provide this control and service quality (Bodvarsson \& Gibson, 1994; Azar, 2009). However, Lynn \& McCall (2000) stated that there is a weak relationship between service quality and tip. This control mechanism may not always improve the service quality. The responsibility of the employer and the business towards the customer can also be transferred to the employee through this mechanism. Whatever the reason for the dissatisfaction of the customer, this responsibility is placed on the shoulders of the employee and the employee pays the price of the dissatisfaction by getting little amount of tip or not getting any tip.

\section{The management's use as controlling}

Enterprises use the tip to establish a wage-cost balance in order to increase their profitability and provide employee control in this way (Ogbonna \& Harris, 2002). The increase in the monthly income of the hotel employees working with low salaries depends on the tip. Employees try to satisfy customers while trying to get more tips to increase their income. In this case, enterprises aim for a good service delivery without the burden of salary increases or additional fees or controlling service encounters. This indicates that businesses use the tip to control employee performance. Participant 27 (female, receptionist) states this situation as follows:

You get a higher fee for the service you provide. You look, I do it somehow better, they give me more money. You think they'll give you more if you do better.

The statement of another participant is as follows: 
[...] our tip box has been opened weekly. If someone scored 1,500-2000 TL tip that week and you have scored $500 \mathrm{TL}$, a race starts and for this reason, you are under psychological pressure. There was a ranking among the tippers. I was feeling bad seeing my name below. So, the tip is good for you to make money. You get greedy, you want to put more money into the tip box (Participant 12 , male, bellboy).

Participants stated that they work more enthusiastically when they get a tip, and they made more efforts to satisfy the guests who tip. Participant 30 said that they serve to each customer up to standard, but she told how the service delivery changes when they get tip:

We actually have standard service. I should not go out of that service, but when someone gives a tip, you are beyond that service. You want to make a gesture. I think the person who says I don't get out of that service is lying (Participant 30, female, waitress).

Tipping can also be used as a competition tool, not only by the management but also by the customer, to have an impact on the employee. Another participant expresses this situation with the following words:

We had a regular customer. Directly after sitting at the table, the woman was putting $50 \mathrm{TL}$ on the table As soon as you see the money while working, you start to move up and down. She was doing something like this. She was putting something on the money so that someone doesn't come and get it right away. I guess, she thought that if someone comes and gets the money right away, then no one will give special attention to her. By putting the money there, she makes everyone pay attention to her. When money is there, everyone starts to pay attention to her, everyone asks if she needs something. Finally, when leaving the table, the woman was choosing a waiter/waitress, and giving the money to him/her (Participant, 21, male, waiter).

\section{Exploitation tool}

Ogbonna \& Harris (2002) stated that some service employees are dissatisfied with the tip system because they think the company policies are exploitative. Similarly, the participants, who consider the tip as an exploitation tool and an instrument used by the employers to keep the salaries low, stated:

We can't really get recompense for our work. The business people and managers think that employees somehow get tips, so they will work even if we give them a low salary. Inevitably, we are dependent upon tips (Participant 3, male, receptionist).
We get the minimum wage. All waiters/waitresses work for the tip. They don't care about their salary. They just think about their tips whether it's $30 \mathrm{TL}$ or $50 \mathrm{TL}$. For example, my first tip was twice my salary (Participant 4, male, waiter).

In addition, the participants stated that customers tip before they get the service with intent to guarantee special attention to themselves. In this way, customers who give pre-service tips try to compel the employees to take more care of themselves.

When the customer tips before the service, I immediately feel strange from his/her. He/she just wants me to show interest in him/her. I am responsible for 8 tables at the restaurant. He/she only wants me to serve him/her after giving 200 TL. Direct bribe! (Participant 14 , male, waiter)

It is a problem that we especially encounter with the local tourists. He/she comes for a 10-day holiday, pays $x$ amount of money, then he/she thinks that he/she bought all the facilities and staff of the hotel because he/she paid $x$ amount of money. He/she pays 10 Euros right after the arrival. Then he/she gets 1000 Euro-worth service from me. He/she presses me into service, he/ she definitely wants something wherever he/she sees me. The reason is that he/she gave me 10 Euro. He/ she wants to get his/her money's worth (Participant 3, male, receptionist).

\subsubsection{Reward}

Azar (2009) and Lynn \& McCall (2000) assert that the tip is a reward given by customers to promote service quality. Mulinari (2016) argues that there is an important difference between the perspectives of customers and employees regarding the question of whether the tip is a reward or wage. He suggests that the tip is an award for the customers to show their satisfaction, and it is a part of their wages for the employees. While customer-focused studies consider the tip as a reward, in this employee-focused study, it is seen that participants consider the tip as part of their salary which is given in return for their labor. From this point of view, while tipping means making an extra contribution to the cost of the service for the customers, no tip means that the payment that they deserve is not fully paid for the employees. Also, Saunders' (2015) study, which shows that the fact that when employees receive more tips than they expect, this does not affect their affactive state, but when they get less than what they expect, then their emotional state will be affected negatively, supports this finding. As a result of the findings ob- 
tained from the participants, the reason why the tip cannot be perceived as a reward by the employees can be grouped under two headings. These are; problems caused by the perception of the tip as a reward and employees' problems related to the tipping systems applied.

\section{Problems caused by the perception of the tip as a reward}

Considering tip as a result of customer's goodwill and magnanimity, but not as the receiving the recompense for employee's labor, causes some problems to arise. Since this point of view is based on asymmetry between the employee and the customer, it may cause some situations that customers assume to be entitled and employees are not satisfied. This study presents two of the most common situations for employees; harassment and the effort of the customer to exert superiority over the employee.

Two participants stated that some of the customers could use the tip maliciously as a harassment tool:

For example, I had a guest, she was quite old, she was in her 50s. She was old to me. While tipping, she was always saying "I wish I would be younger. She would tip me for this reason (Participant 17, male, waiter).

I was a stewardess where I first worked. I was not serving personally to the customers and I was telling it to them. I didn't know the waitering. The customer insistently called me to take care of him. He said to me "Let me give you 5 dollars and stay with me for 5 minutes". There were such guests. That year I was so dissatisfied with my job. I cried and I told that I would leave the job to the manager. Then, the F\&B manager spoke to the guest, who did the same to my other co-workers. Because, as the stewardesses, they gave us very short skirts and we were wearing high heels (Participant 18, female, waitress).

Participants often identified tipping with customer's effort to exert superiority over the employee. Employees attribute importance to the way the tip is given, because it is considered as an indicator of the perception of the tip. While the tip that given to the employee by thanking as a result of the service satisfies the employees, the other styles of tipping are found embarrassing by the employees. Many of the participants expressed their opinion on this situation. Here are a few expressions that are thought to stunning:

There is a tip for a job you do in a friendly way. There is also tipping by showing that I am superior to you. The satisfaction level for both styles is different. Even if so- meone gives you a very high amount of tip, for example, 100 Euros, you say that he/she would have not given that tip by remembering it badly. But a friendly given 5 Euro can change everything. So, money is not everything, money does not provide you the job satisfaction, but the behaviors of people do. I think the tip should be given by making you feel like you deserved it (Participant 13, male, bellboy).

Some people are embarrassed when reaching the tip up to you. Sometimes even some customers give a high amount of tip, they give it by thinking that's not enough and some other customers just throw it onto the tray. Some customers react like "come on, take it!". And customers who consider the tip as a favor usually treat us like so to speak"I gave you 50TL, so you'll be like a dog, you will do what I want and you will always give priority to my wants" (Participant 31, female, bar chief).

Some of them have very harsh temperament. He/ she give the tip as if he/she gives it to a beggar. He/she doesn't even look at your face. Actually, they shouldn't hurt me, should be smiling and give it by making me feel that I don't need it (Participant 18, female, waitress).

\section{Tipping systems and problems encountered}

There is a wide variety of tipping systems in businesses around the world. However, in light of the data obtained from the experience of the participants, we mainly note two types of tipping systems: individual and pooled tipping (Namasivayan \& Upneja, 2008). While individual tipping means that employees will have their own tips, pooled tipping is the collection of all the tips in one place and the distribution of them to the employees according to the distribution system of the enterprise. Even though individual tipping doesn't cause a fairness problem, it causes difficulties on the distribution of shifts with higher tips, the selection of the employee that serves to a customer who gives a high amount of tip or willingness to work in the department with more tips. However, pooled tipping doesn't always satisfy the employees in the process of sharing the collected tips. All the participants, including the employees who consider the tip as an earned income, emphasized that the way the tip is given or how it is shared is very important.

Almost all of the participants stated that they have worked in very different systems and experienced both main tipping systems. The number of participants who agree that the pooled tipping system will be better is slightly more than those who prefer individual tipping. The reasons for the participants who stated that the 
individual tipping system would be more successful are as follows:

I get the highest amount of tip, but my friend does nothing. How can I share my earning with him/her? I think it would be unfair (Participant 21, male, waiter)

For example, we had a manager. He was just playing backgammon, standing up and not doing anything. During the tip sharing, his sharing rate was ten and mine was 6. I was feeling offended. Naturally, you want your due and if we work there we should have a fair sharing rate accordingly (Participant 2, male, waiter)

Although, in their study, Namasivayam \& Upneja (2008) stated that American employees consider the pool system as the most unfair and worst system in terms of distributional justice, employees working in Turkey and most of the participants stated that pooled tipping system is fair. Participants, who think that the pooled tipping system is fair, stated:

When there is no pooled tipping system, there is definitely a fight or a discussion between the staff. Besides, if the tables you serve is better than the others, waiters/waitresses want to serve these tables. This causes some problems. If there is a pooled tipping system, then employees trust themselves, trust their friends. And also at the reception, there is the night shift, at the night shift, there is no entrance or exit, nobody, no money and no tip. Nobody wants to work at the night shift, everyone wants to work at the day shift. This is unfair. So, the pooled tipping system makes the most sense (Participant 6, male, waiter).

For example, a guest, who gives a tip, sits at the table which I serve, but the next day he may not sit at that table. This situation can sometimes turn into the stealing customers by the waiters/waitresses. You know the guest who gave tip and this guest is a repeat customer. You serve this guest by knowing who he/she is. But there are such waiters/waitresses who stick to the guest even at the entrance and call the guest to the table they serve. Therefore, individual tipping system is not fair (Participant 29, male, waiter).

\subsection{When Do Customers Tip?}

Customers'tipping behaviors vary according to the factors that depend on the employees and customers themselves. Besides, participants stated that apart from their general attitude, customers are more generous about tipping on special days such as feast, valentine's day, new year. If we put such special situations aside, we can divide the factors that determine the tipping into two groups as customer-oriented and employee-oriented.

\section{Customer-oriented factors}

Employees specified the factors that positively affect customers'tipping behavior as follows: (1) Having a tipping habit (2) Feeling special (3) Being drunk (4) Making a show of to the person or people with him/ her (5) Having a good mood (6) Having a friendly and caressing attitude towards employees (7) Being rich (8) Overspending or having a high amount of bill.

Similarly, Lynn \& McCall (2016) found that bill size is the most important factor affecting the amount of tip, and that the mood of the customer during the service encounter has a significant effect on the amount of tip. The findings of Sanchez (2002) that alcohol-consuming customers give more tips and the findings of Shamir (1984) that customers use tipping as a power/status indicator support the statements of participants.

Participant 6's statement about how drunkenness affects tipping behavior is as follows:

A customer is more likely to tip when he/she is drunk. Because he/she doesn't remember, can't see things right, doesn't know. Probably, the next day he/ she doesn't remember it and tip more (Participant 6, male, waiter).

In addition, the participants underlined that the most important factor in the formation of the tipping behavior of the customer is the tipping habit. Because in this case, whatever the employees do, the customer will tip.

The customer who tips will already tip, he/she will tip anyway (Participant 3, male, receptionist).

While most of the participants stated that customers tip when they feel special, and emphasized that what they mean by feeling special is that customers feel more privileged than other customers. Some of the participants stated that they serve above the standards to some customers that they think will tip. Participant 12 , stated how they estimate which customer will tip and how they treat them:

His/her car, his/her clothes, how many suitcases he/ she came with, even the brand of his/her suitcases can be important for us. Because there are $100 \mathrm{TL}$ worth suitcase and $500 \mathrm{TL}$ worth suitcases. We know them already. There are suitcases like a metal case. These draw our attention during the entrances and exits. Even though we are busy when they leave the hotel and 
other rooms are waiting for us, we give them water or wet wipes or towels and we say "please come again". If he/she is going to the airport from the hotel, we tell $\mathrm{him} /$ her how to go there or give information about the transfer car of the hotel. We explain everything and he/ she sees it because we really make other guests while we are taking care of him/her. We can get more tips by doing that (Participant 12, male, bellboy).

Employees who conveyed their experiences about the cases when customers tip more, also stated that the approach and attitude of the customers to the employee is decisive and the current mood of the customer is an important factor determining the amount of tip:

There are guests who are constantly bossing over and are not satisfied with anything. Whatever you do, you cannot satisfy him/her. It is also not possible for him/her to tip (Participant 10, female, restaurant chief).

While showing the room to the guest, his/her mental state is important. It is obviously up to the customer whether he/she tips. Is she/he travel-worn, how is his/ her mood, how does he/she feel? (Participant 12, male, bellboy).

Another participant emphasized that customers tip to show off to people who are next to them:

For example, $\mathrm{X}$ (a famous person) came to our hotel, he was over 70 years old. He came every day with a different 18-year-old girl. When I say "Mr. X, welcome", he tips, when I say "Mr. X goodbye", he tips. ... There are people who tip just to show off (Participant 1, male, waiter).

A tip is given to the vale. This habit is already adopted. I say especially for the city hotels, a man comes with a woman, tries to impress the woman, gives you 200 TL just because you handed the car key when he is next to that woman. Under normal circumstances, this man doesn't give you even 1 TL. Some guests do this, too. For example, some guests give tips to the employee who serves them just to be greeted with his name. To make the employee say "Welcome, Mr. X". Not for service. It is enough for him to make the employee advertise him to the man next to him. (Participant 3, male receptionist).

\section{Employee-oriented factors}

When the employees stated the factors related to them about factors that affect tipping behavior positively, they emphasized respectively the importance of; (1) Smiling (2) Acting warmly and sincere (3) Making extra effort apart from the main service (4) Looking tired (5) Providing a service of good quality (6) Looking clean and well-groomed

Many of the employees stated that smiling affects customers' tipping behavior. Participant 28 stated that not just smiling, but a warm smile is effective on customers' behavior as Bujisic et al. (2013) suggested. Participant 29 emphasized that smiling is a necessity:

The come here somehow to satisfy their ego. Because they think that they are on vacation, they pay for the service, so employees have to smile and they are right. I also don't want a waiter/waitress, who is not smiling, to serve me (Participant 29, male, waiter).

The customer is always ready to tip. How can I say, for example, the guest came, first of all, you have to welcome him/her in a friendly way. After you make that friendly welcome, the guest is already starting to warm to you. As you serve, they start to think about tipping. They tip in that way, too. (Participant 25, male, waiter).

Although Prett (2015) claims that beauty affects customers' tipping behavior, most of the participants stated that not beauty, but looking clean and well-groomed can positively affect the customers'tipping behavior. In addition, many of the participants surprisingly stated that customers tip more when the employees look tired. As Saunders \& Lynn (2010) stated, this may be due to customers' willingness to help employees. Participant 6 expressed this situation as follows:

The person next to you has the perception that you are a laborer. This makes him/her to tip more. For example, we work 8 hours a day in our hotel. The guest sees you at 12 o'clock at night, and he/she sees you at 8 o'clock in the same place, He/she asks "Are you still here?". Then, when there are a few works to do, they have the feeling to tip. In fact, it seems like they feel bad for us a little bit (Participant 6, male, waiter).

\subsection{Employees' Tipping Strategies}

Employees stated that there was a group of behavioral patterns and strategies they developed to receive a tip. Even the participants, who told that they do not have a strategy to get a tip, talked about what they do to get more tips later during the interview. Based on the statements of the employees, the strategies they applied the most were; (1) to be warm and sincere, (2) to smile, (3) to offer various treats, (4) to make them feel special, (5) to be nice, (6) to communicate by knowing their names, (7) trying to increase the amount of the bill, (8) chatting, (9) making a joke. Some examples of these strategies given by the participants are striking: 
I will tell you the most effective strategy, you have to receive an order from the guest just once. Later, if you know what he/she wants to eat or drink, and you bring it without saying, you have always the chance of getting tip [...] You will greet him/her with his/her name and say good morning then let him/her seat at the table, then you will bring his/her order directly without receiving an order. You will get your tip with a $100 \%$ possibility (Participant 10 , female, restaurant chief).

When I say "Hello, welcome, sir, let me bring your drink", they look at me and get surprised. The people next to him think that he is there every day. This situation nobilitates him when they are with his friends. Therefore, he tips (Participant 5, male, waiter).

Findings that participants get more tip by being cute and increasing the amount of bill size through increasing sales are similar to the results of the meta-analysis study conducted by Lynn \& McCall (2016). Participants' statements that indicate the amount of the bill size is important for getting a tip is as follows:

I recommend to the customer the most expensive meal, for example, I sell lobster, fish. For example, the customer wants pasta, then I recommend the pasta with lobster (Participant 1, male, waiter).

Besides, participants emphasized that it is an important strategy to treat what customers actually do not what but what employees think that they might like. Participant 31 stated the importance of treats as follows:

For example, when you serve whiskey, there is no side chocolate. I always have a couple of chocolate bars I buy from the market. I buy it myself. I give these chocolate bars to the customers who I know before. So, I do something extra. There are nuts at the hotel, but nuts aren't good with whisky, chocolate is better. If I know that the customer tips, I serve him/her chocolate with whiskey (Participant 31, female, bar chief).

In addition, as can be understood from the statement of Participant 30, employees told that customer satisfaction differs from customer to customer, therefore it is necessary to act by trying to understand what customer wants. Participant 32 stated that it would be wrong to get a tip paying attention to every customer more than they expected, employees should treat differently by recognizing the customer whether he/she is thought to be satisfied with more attention or not:
Some guests enjoy being interested. You do everything for them. You need to know the guest's wants. Because some customers' attitudes show you that you should serve and go away. You understand that over time. If there are customers who wait for extra service, you bring their wet wipes, toothpicks etc. without ordering. Actually, there is no need for a toothpick. The guest did not eat meat, he ordered some dessert or tea, but you bring him a toothpick. This means that I give you an extra service and I want something in return (Participant 30, female, waitress).

I'd try a joke first, if the customer likes it, then go ahead. Sometimes when I joke, the customer doesn't like it, some people like discipline. Then I try to behave like what the customer wants (Participant 32, male, receptionist).

\section{Conclusion and Discussion}

Due to the limited number of studies dealing with the topic of tipping from the employee perspective or studies dealing only with how employees perceive the tip and why they prefer tip, this study aimed to fill the gap in the literature. The current study investigates all aspects of how the employees perceive the tip, why customers tip and which strategies employees use to get tip.

Ogbonna \& Harris (2002) argued the rewarding and motivation of employees related to wages policies in competitive environments, therefore it is important to investigate tipping behavior. The importance of this study is to deal with how the tip is perceived from the employee perspective with reference to employees' feelings, opinions and experiences working at hotels in Turkey. According to the findings of this study, employees stated that they perceive the tip as a wage and customers stated that they consider the tip as a reward. Also, employees have mentioned the distress caused by the customers who perceive the tip as a reward (harassment and the effort of the customer to exert superiority over the employee). The tip concept differs from culture to culture as wells as between different professions within the same culture. Therefore, tipping can be seen as a wage they deserve in return for their labor by the employees as well as a tool for exploitation and harassment, a noiance increasing the competition among employees, a factor increasing the domination of the employer over the employees. Especially participants, who define the tip as their deserved wages (Mulinari, 2016), stated that the tip increases their motivation when it is fairly shared or 
given in a way that does not hurt themselves. This is an indication that the way or the fair distribution of the tip is more important and motivating for the employees rather than the amount of tip. As stated by Ogbonna \& Harris (2002), the definition of the tip as an instrument of exploitation by the same participants in the study indicates that there is no established norm in Turkey and the industry regarding the nature of the tip. Based on this study, which deals with the perceptions of employees towards tipping in the hospitality industry, we can say that the industry needs some normative regulations regarding tipping.

While tipping is unacceptable in some countries such as Japan, it has become an obligation in countries like the USA (Ferguson et. al., 2017). Azar (2004) defines the situation that tipping is an obligation in the USA as becoming a social norm. While tipping is already presupposed in cultures where it is accepted as the social norm, the studies usually focus on the amount of tip. There is no study examining whether tipping is a social norm or how it is perceived in Turkey. However, we cannot assert that there is a common acceptance that tipping is a social norm with reference to statements of participants about customers' tipping behaviors. Unlike countries that accept tipping as a social norm, the tip is not still considered as an obligation in Turkey. Thus, we can say that Turkey's perception of the tip lays between the perception of countries that find tipping unacceptable and countries that accepts tipping as a social norm. Tipping is neither an obligation nor an unacceptable thing. For this reason, in regards to the place, tipper, employees etc., it is sometimes seen as something humiliating and sometimes as a shame when not tipping. Therefore, in order to investigate the tip concept in a more comprehensive way in Turkey, there is a need for multidimensional studies addressing all the dynamics (customer, profession, workplace, region etc.) that determine the tip perception.

As stated above, employees divide factors that determine tipping behavior into two groups as customer and employee-oriented and based on these dynamics, they develop strategies to increase their income. A normative structure developed by the sector will prevent the different practices that lead to such strategies, as well as the negativity related to the tipping that some participants stated. If the businesses have such tipping policies and inform customers about their policy, it will eliminate the uncertainty for the employees and in some cases the unpredictability for the customers. Indeed, the need for a normative arrangement for collecting tips in a pooled system, provided that the tip is shared fairly, can be considered as a sign of the need for companies to form their tipping policies. Of course, it will be possible to transform these suggestions into concrete suggestions only with the results of the comprehensive studies and negotiations. However, starting from this study, it is essential to take into account serious problems (such as the tip becoming a means of exploitation and control, enabling harassment, eliminating employer's responsibility to the customer and the employee) and the issues about tipping stated by the participants. 


\section{References}

Altunışık, R., Çoşkun, R., Yildirim, E. ve Bayraktaroğlu, S. (2012). Sosyal Bilimlerde Araştırma Yöntemleri. (7. Baskı), Sakarya: Sakarya Kitabevi.

Atkinson,R.\& Flint, J. (2001). Accessing Hidden and Hard-to-Reach Populations: Snowball Research Strategies,. Social Research Update, 33, 1.

Azar, O.H. (2003). The Implications of Tipping for Economics and Management. The International Journal of Social Economics 30, 1084-1094.

Azar, O. H. (2004). What Sustains Social Norms and How They Evolve?: The Case of Tipping. Journal of Economic Behaviour \& Organization, 54(1): 49-64.

Azar, O.H. (2005). Who Do We Tip and Why? An Empirical Investigation", Applied Economics, 37(16): 1871-1879.

Azar, O. H. (2009). Incentives and Service Quality in The Restaurant Industry: The Tipping-Service Puzzle. Applied Economics, 41(15), 1917-1927.

Azar, O. H. (2010a). Do People Tip Because of Psychological or Strategic. Applied Economics, 42(23): 3039-3044.

Azar, O. H. (2010b). Tipping Motivations And Behavior in the US And Israel", Journal of Applied Social Psychology, 40(2):421 - 457.

Azar, O. H. (2011). Business Strategy and the Social Norm of Tipping. Journal of Economic Psychology, 32: 515-525.

Bodvarsson, B \& Gibson, W. A. (1994). Gratuities and Customer Appraisal of Service: Evidence from Minesota Restaurants. The Journal of Socio-Economics, 23(3): 287-302.

Bujisic, M., Wu, L., Mattila, A. \& Bilgihan, A. (2013). Not All Smiles are Created Equal Investigating The Effects of Display Authenticity and Service Relationship on Customer Tipping Behavior. International Journal of Contemporary Hospitality Management, 26 (2):293-306.

Curtis, C. R., Upchurch, R.S \& Severt, D. E. (2009). Employee Motivation and Organizational Commitment: A Comparison of Tipped andNontipped Restaurant Employees. International Journal of Hospitality \&amp; Tourism Administration, 10:3, 253-269.

Crespi, L. P. (1947).The Implications of Tipping in America. Public Opinion Quarterly, 11: 424-435.

Ferguson, G., Megehee, C. M.\& Woodside, A. G. (2017). Culture, Religiosity, And Economic Configural Models Explaining Tipping-Behavior Prevalence Across Nations. Tourism Management, 62: 218-233.
Gueguen, N.\& Jacob, C. (2014). Clothing Color and Tipping: Gentlemen Patrons Give More Tips to Waitresses with Red Clothes. Journal of Hospitality \& Tourism Research, 38(2): 275-280.

Isik, C, Dogru, T, Turk, E, S. (2018). A Nexus of Linear and Non-Linear Relationships Between Tourism Demand, Renewable Energy Consumption, and Economic Growth: Theory and Evidence. International Journal of Tourism Research, 20: 38- 49.

Jacob, C., Gueguen, N., Boulbry,G.\& Ardiccioni, R. (2010). Waitresses' Facial Cosmetics and Tipping: A Field Experiment. International Journal of Hospitality Management, 29: 188-190.

Lynn, M., \& Graves, J. (1996). Tipping: An Incentive/Reward for Service? Journal of Hospitality and Tourism Research,, 20(1): 1-14.

Lynn, M. (1997). Tipping Customs and Status Seeking: A Cross-Country Study. International Journal of Hospitality Management, 16(2): 221-224.

Lynn, M., \& McCall, M. (2000). Gratitude and Gratuity: A Meta-Analysis of Research on the Service-Tipping Relationship. Journal of Socio-Economics, 29 (2).

Lynn, M. (2015). "Service Gratuities and Tipping: A Motivational Framework", Journal of Economic Psychology,46: 74-88. doi: 10.1016/j.joep.2014.12.002.

Lynn, M.\& McCall, M. (2016). Beyond Gratitude and Gratitude and Gratuity: A Meta-Analytic Review of the View of the Predictors of Restaurant Tipping. Working Paper No. 21, Cornell University. Accessed April 22, 2019.

Mulinari, P. (2016). Weapons of the Poor:Tipping and Resistance in Precarious Times", Economic and Industrial Democracy, . doi:10.1177/0143831X16653188

Namasivayam, K. \& Upneja, A. (2008). Employee Preferences for Tipping System, Journal of Foodservice Business Research, 10(2): 93-107.

Ogbonna, E. \&Harris, L. C. (2002). Institutionalization of Tipping as a Source of Managerial Control. British Journal of Industrial Relations , 40(4):725-752.

Parasuraman, A., Zeithaml, V. and Berry, L. (1988). SERVQUAL: Multiple-Item Scale for Measuring Consumer Perceptions of Service Quality. Journal of Retailing, Vol. 64 (1):12-40.

Parett, M. (2015). Beauty and the Feast: Examining The Effect of Beauty on Earnings Using Restaurant Tipping Data. Journal of Economic Psychology, 49: 34-46. 
Saunders, S. G., \& Lynn, M. (2010). Why Tip? An Empirical Test of Motivations for Tipping Car Guards. Journal of Economic Psychology, 31(1): 106-113.

Saunders, S. G. (2015). Service Employee Evaluations of Customer Tips: An Expectations-Disconfirmation Tip Gap Approach. Journal of Service Theory and Practice, 25(6):7 96-812.

Sanchez, A. (2002). The Effect of Alcohol Consumption and Patronage Frequency on Restaurant Tipping. Journal of Foodservice Business Research, 5(3):19-36.

Segrave, K. (2009). Tipping: An American Social History of Gratuites. Mc Farland \& Company: London

Seiter, J.S. (2007). Ingratiation and Gratuity: The Effect of Complimenting Customers on Tipping Behavior in Restaurants. Journal of Applied Social Psychology, 37(3): 478-485.
Seiter, J.S.\&Weger, H. (2018). The Principle of Reciprocity in Hospitality Contexts: The Relationship Between Tipping Behavior and Food Servers' Approaches To Handling Leftovers. Journal of Hospitality \& Tourism Research, 42,(2): 287-294.

Shamir, B. (1984). Between Gratitude and Gratuity: An Analysis of Tipping. Annals of Tourism Research, 11: 59-78.

Star, N. (1988).The International Guide to Tipping, NewYork: BerkleyBooks.

Tse, A. C. (2003) Tipping Behaviour: A Disconfirmation of Expectation Perspective. Hospitality Management, 22: 461-567. 